\title{
Halogen-Dependent Surface Confinement Governs Selective Alkane Functionalization to Olefins
}

\author{
Guido Zichittella, ${ }^{+}$Matthias Scharfe, ${ }^{+}$Begoña Puértolas, Vladimir Paunović, Patrick Hemberger, \\ Andras Bodi, László Szentmiklósi, Núria López, and Javier Pérez-Ramírez*
}

\begin{abstract}
The product distribution in direct alkane functionalization via oxyhalogenation strongly depends on the halogen of choice. Herein, we demonstrate that the superior selectivity to olefins over an iron phosphate catalyst in oxychlorination is the consequence of a surface-confined reaction. Oppositely, in oxybromination alkane activation follows a gas-phase radical-chain mechanism, yielding a mixture of alkyl bromide, cracking, and combustion products. Surface coverage analysis of the catalyst and identification of gas-phase radicals in operando mode are correlated to the catalytic performance by a multi-technique approach, which combines kinetic studies with advanced characterization techniques, such as prompt-gamma activation analysis and photoelectron photoion coincidence spectroscopy. Rationalization of gas-phase and surface contributions by density functional theory reveals that the molecular level effects of chlorine are pivotal in determining the stark selectivity differences. These results provide a strategy that enables to unravel a detailed mechanistic picture in a complex reaction network.
\end{abstract}

The development of novel technologies for the selective functionalization of light alkanes is a critical step to enable the utilization of natural gas as an energy vector in the transition between the oil and the renewables era. ${ }^{[1]}$ This pivotal advancement is limited by our understanding of the mechanisms governing the heterogeneously-catalyzed reactions for direct hydrocarbon upgrading, which can provide design criteria for active, selective, and stable catalysts. In the case of light alkane functionalization, generally requiring high temperatures and/or aggressive reactants, the level of complexity is further amplified by the possibility of gas-phase reaction pathways, in which highly reactive radical species and/or radical initiators are liberated from the surface, generating desired and undesired products. ${ }^{[2]} \mathrm{A}$ high level of selectivity control could be achieved, if alkane activation were confined on a catalyst surface. However, to unravel reaction pathways, as well as reactive intermediates in gaseous and solid phases, and to model complex and dynamic surfaces at the atomic level, the combined use of strong experimental evidence with advanced theoretical approaches is a prerequisite. Recently, catalytic oxychlorination, comprising the reaction of an alkane with $\mathrm{HCl}$ and $\mathrm{O}_{2}$, has been demonstrated to selectively ( $\left.\geq 95 \%\right)$ generate ethylene from ethane over a wide range of catalyst families ${ }^{[3]}$ while the use of $\mathrm{HBr}$ as a halide source always resulted in a spectrum of products, comprising mainly alkyl bromide, $\mathrm{CH}_{4}$, and carbon oxides among others. ${ }^{[4]}$ To understand the mechanistic origin of such selectivity control, we combined kinetic studies with operando surface coverage quantification by prompt-gamma activation analysis (PGAA) and gas-phase radicals monitoring by photoelectron photoion coincidence spectroscopy (PEPICO), which were ultimately rationalized at the molecular level by density functional theory (DFT) calculations over an iron phosphate catalyst (Figure 1). This material was chosen due to its ability to selectively $(\leq 97 \%)$ generate ethylene and propylene via alkane oxychlorination. ${ }^{[3]}$ Performance assessment in ethane oxychlorination (EOC) and oxybromination (EOB) under variable temperatures (573-853 K) revealed that the light-off curve for oxybromination was shifted to ca. $150 \mathrm{~K}$ lower temperature compared to that obtained in oxychlorination (Figure 2a), in agreement with previous observations on other materials. ${ }^{[4 b]}$ Characterization of the material before and after catalysis by means of $\mathrm{N}_{2}$ sorption, X-ray diffraction (XRD), and Raman spectroscopy revealed that the textural properties and the crystallographic structure were preserved (Figure S1, Table S2 see the Supporting Information). A comparison of the selectivity patterns obtained at similar alkane conversion level (ca. 20\%) showed that $\mathrm{C}_{2} \mathrm{H}_{4}$ is the major product (selectivity ca. $95 \%$ ) when $\mathrm{HCl}$ is used as a halide source, while oxybromination led to the formation of $\mathrm{C}_{2} \mathrm{H}_{5} \mathrm{Br}, \mathrm{CH}_{4}$, carbon

$\left.{ }^{[*}\right] \quad$ G. Zichittella, ${ }^{[+]}$M. Scharfe, ${ }^{[+]}$, Dr. B. Puértolas, Dr. V. Paunović, Prof. J. Pérez-Ramírez Institute for Chemical and Bioengineering

Department of Chemistry and Applied Biosciences, ETH Zurich Vladimir-Prelog-Weg 1, 8093 Zurich (Switzerland)

E-mail: jpr@chem.ethz.ch

Dr. P. Hemberger, Dr. A. Bodi

Laboratory of Femtochemistry and Synchrotron Radiation

Paul Scherrer Institute, 5232 Villigen (Switzerland)

Dr. L. Szentmiklósi

Nuclear Analysis and Radiography Department

Centre for Energy Research, Hungarian Academy of Sciences

Konkoly-Thege Miklósi út 29-33, 1121 Budapest (Hungary)

Prof. N. López

Institute of Chemical Research of Catalonia

The Barcelona Institute of Science and Technology

Av. Països Catalans 16, 43007 Tarragona (Spain)

[+] These authors contributed equally to this work. oxides, and $\mathrm{C}_{2} \mathrm{H}_{4}$ (Figures $\mathbf{2 b}$, S2). Both reactions are believed to follow a consecutive mechanism, where the alkyl halide is the intermediate to the olefin (Figure S2). Nevertheless, the observed selectivity differences might be caused by the more kinetically favorable elimination of $\mathrm{HCl}$ compared to $\mathrm{HBr}$ over a catalyst surface, as shown in catalytic methyl halide coupling. ${ }^{[5]}$ To probe this hypothesis, we conducted ethyl halide dehydrohalogenation to $\mathrm{C}_{2} \mathrm{H}_{4}$ over $\mathrm{FePO}_{4}$ (Figure S3), and observed that the light-off curve for $\mathrm{C}_{2} \mathrm{H}_{5} \mathrm{Cl}$ dehydrochlorination was shifted by $c a .40 \mathrm{~K}$ to lower temperature compared to $\mathrm{C}_{2} \mathrm{H}_{5} \mathrm{Br}$. When $\mathrm{O}_{2}$ and $\mathrm{HX}$ were co-fed with ethyl halide over $\mathrm{FePO}_{4}$ (Figure 2c), dehydrochlorination led mainly to $\mathrm{C}_{2} \mathrm{H}_{4}$, while a competition between polybromination and dehydrobromination was evidenced for ethyl bromide. Additionally, catalytic hydrogen halide oxidation and gas-phase ethane halogenation were investigated in order to measure the ability of the catalyst to produce molecular halogen and the intrinsic reactivity of the halogen with the alkane at comparable conditions to oxyhalogenation (Figures 2a, S4). While chlorine-based 


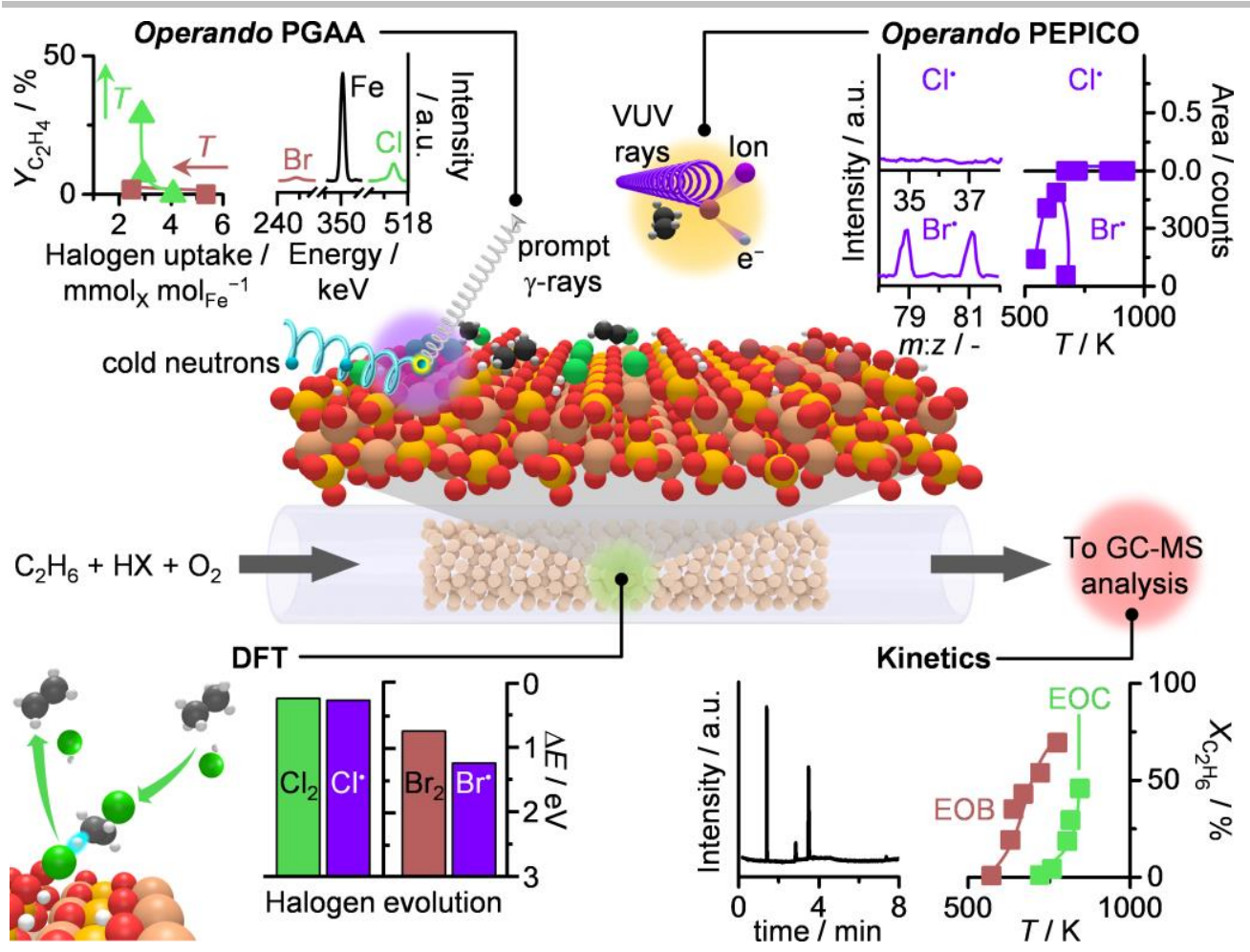

Figure 1. Schematic representation of the multi-technique strategy used in this study that enabled to unravel the surfacedriven and gas-phase radical-chain pathways through which alkane activation occurs in catalytic ethane oxyhalogenation. This approach concertedly combined (I) kinetic analysis for assessment of catalytic activity and selectivity patterns with operando (ii) PGAA and (iii) PEPICO spectroscopies, enabling quantification of the surface composition and detection of gaseous intermediates, respectively, ultimately rationalized by (iv) DFT. Each of these techniques results into spectra or energy levels (inner graphs) that can be subsequently evaluated and/or correlated to observable parameters (outer graphs), revealing a detailed mechanistic picture for a complex chemical process. reactions occurred in distinct temperature regions, the bromine-based analogues overlapped, evidencing that adsorbed $\mathrm{HCl}$ cannot evolve as $\mathrm{Cl}_{2}$ from the catalyst under typical oxychlorination conditions, in contrast to $\mathrm{Br}_{2}$ that can be generated during oxybromination.

These findings suggest that ethane oxychlorination could occur via a surface-driven mechanism, in which the adsorbed chlorine species might be important for the catalyst performance. On the contrary, gas-phase bromination with in situ generated bromine species is likely the preferred pathway for ethane activation in oxybromination.

To address the impact of the halogen coverage on the performance, we conducted PGAA spectroscopy under operando conditions, whose working principles are schematized in Scheme S1 and for which $\mathrm{FePO}_{4}$ is a suitable material due to its moderate neutron-capture cross section. ${ }^{[6]}$ The experimental setup comprises a continuous-flow tubular reactor, where the catalyst is non-destructively irradiated with cold neutrons, ${ }^{[7]}$ which are captured by the nuclei of all atoms in the sampling volume during the oxyhalogenation reaction. The de-excitation of the thus formed compound nuclei results into emission of prompt $\gamma$-rays with elementspecific energies and with intensities that are proportional to the number of emitting atoms (Figure 1). The quantified halogen uptake with respect to iron at variable temperatures and inlet $\mathrm{HX}$ concentrations is correlated to the yield of ethylene in Figure 3 . In particular, at the onset of oxychlorination, $\mathrm{FePO}_{4}$ exhibited ca. $4.1 \mathrm{mmol}_{\mathrm{Cl}} \mathrm{mol}_{\mathrm{Fe}}{ }^{-1}$, corresponding to $76 \%$ of surface iron sites occupied by chlorine. The rise of the reaction temperature led to the increase of the yield of ethylene increased while the chlorine uptake decreased to ca. $3 \mathrm{mmol}_{\mathrm{Cl}} \mathrm{mol}_{\mathrm{Fe}}{ }^{-1}$, equivalent to $55 \%$ surface coverage, and remained constant at higher temperatures. On the other hand, the bromine uptake at the onset of oxybromination at $573 \mathrm{~K}$ reached ca. $5.4 \mathrm{mmol}_{\mathrm{Br}} \mathrm{mol}_{\mathrm{Fe}}{ }^{-1}$, equivalent to full coverage, which drastically decreased to $2.5 \mathrm{mmol}_{\mathrm{Br}} \mathrm{mol}_{\mathrm{Fe}}{ }^{-1}$ at $633 \mathrm{~K}$. Further increase in temperature to $723 \mathrm{~K}$ did not allow bromine uptake quantification, due to statistically negligible halogen content, as corroborated by the absence of bromine in the used catalyst by means of elemental analysis (Table S2). Interestingly, an increment of the halide feed resulted in an increased olefin yield that correlated with a higher halogen coverage in oxychlorination, while the opposite trend was observed in oxybromination. In order to translate these observations into causality correlations, density functional theory calculations were performed on the experimentally relevant (102) surface of trigonal FePO $\mathrm{P}_{4}$ (Figure S1). $\mathrm{Cl}_{2}$ and $\mathrm{Cl}^{\circ}$ desorption are endothermic by $2.70 \mathrm{eV}$ and $2.66 \mathrm{eV}$, respectively, indicating that chlorine atoms are persistent on the surface. In contrast, bromine can desorb as $\mathrm{Br}_{2}(\Delta E=2.10 \mathrm{eV})$, and even more favorably as $\mathrm{Br}^{\circ}(\Delta E=1.52 \mathrm{eV}$, vide infra Figure 5 , Figure S5). Therefore, the evolution of bromine species is much more energetically favored compared to chlorine counterparts, which explains the lower surface bromination under comparable reaction conditions (Figures 2a, 3, S5). These results suggest that gas-phase pathways can be initiated by the formation of bromine radicals, which were evidenced by the detection of $\mathrm{Br}_{2}, \mathrm{Br}^{\circ}$ and $\mathrm{C}_{2} \mathrm{H}_{5}{ }^{\circ}$ radicals by operando PEPICO (Figures 4, S6-S9), a spectroscopic technique that has been recently applied to provide evidence of the gas-phase radical-chain routes in methane oxybromination, ${ }^{[2 \mathrm{e}]}$ and schematized in Scheme S2. Therein, the gaseous species exiting the PEPICO reactor form a molecular beam, which is skimmed and ionized by monochromatic vacuum ultraviolet (VUV) radiation, yielding photoelectrons and photoions that are detected in delayed coincidence, allowing isomer-selective identification of reactants 

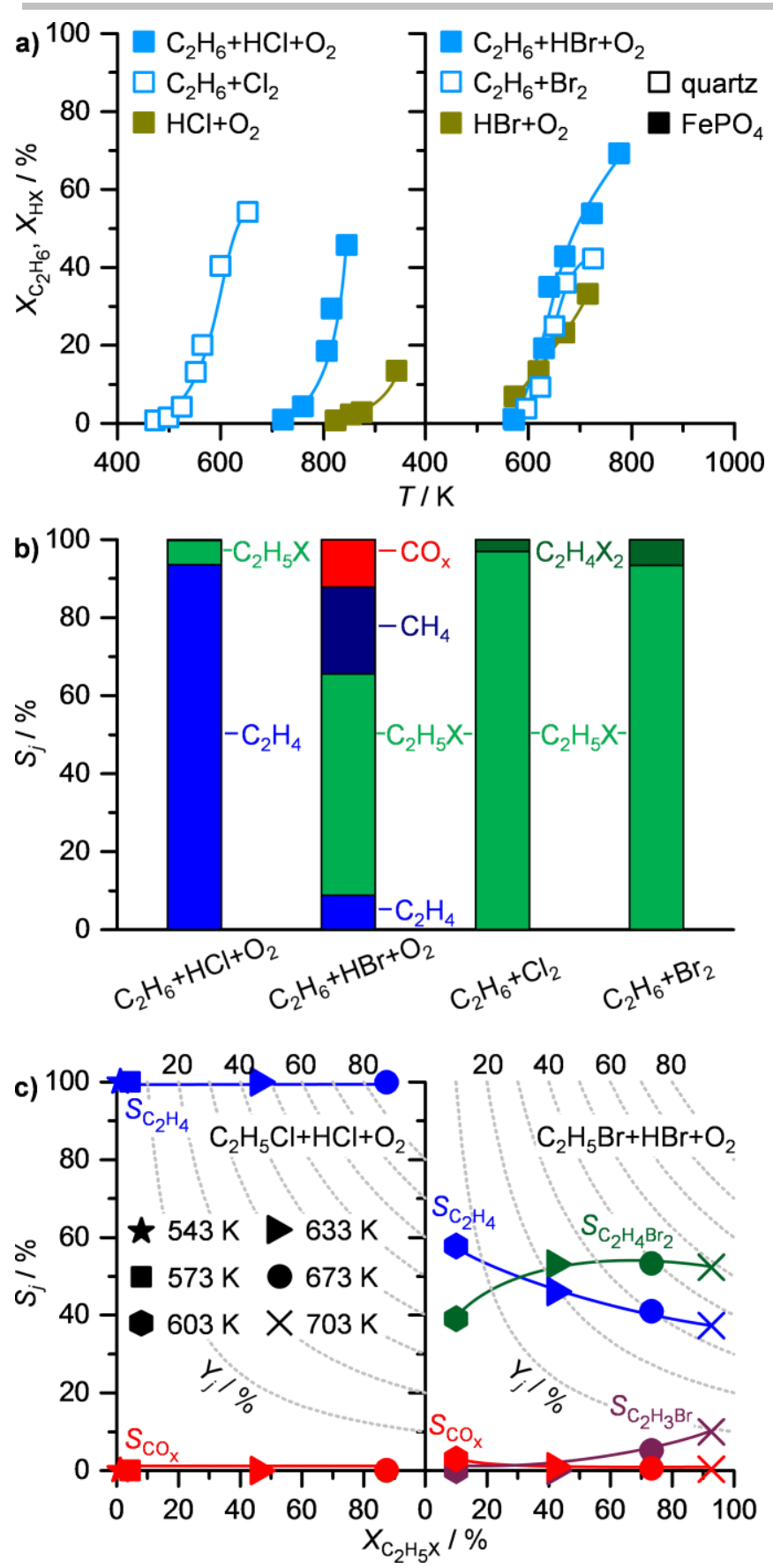

Figure 2. a) Ethane conversion as a function of temperature in oxyhalogenation over $\mathrm{FePO}_{4}$ and in non-catalytic ethane halogenation over inert quartz particles, and hydrogen halide conversion as a function of temperature in $\mathrm{HX}(\mathrm{X}=\mathrm{Cl}, \mathrm{Br})$ oxidation over $\mathrm{FePO}_{4}$, showing that these reactions occurs in distinct temperature regions with chlorine chemistry while they overlap with the bromine one. b) Selectivity patterns obtained in catalytic ethane oxyhalogenation and non-catalytic ethane halogenation at ca. $20 \%$ ethane conversion, illustrating that only ethane oxychlorination leads to selective ethylene generation. c) Selectivity to products as a function of ethyl halide conversion in the dehydrohalogenation of ethyl halide in the presence of $\mathrm{HX}$ and $\mathrm{O}_{2}$ over $\mathrm{FePO}_{4}$, showing that ethylene generation is favored with an ethyl chloride intermediate over its brominated counterpart. The dotted gray lines denote the yield of product $j$ and the different symbols refer to the reaction temperature. Conditions in a) and $\mathbf{b}$ ): $\mathrm{C}_{2} \mathrm{H}_{6}: \mathrm{HX}\left(\mathrm{X}_{2}\right): \mathrm{O}_{2}: \mathrm{Ar}: \mathrm{He}=6: 6(3): 3(0): 4.5: 80.5(89.5), \quad F_{\mathrm{T}}=100 \mathrm{~cm}^{3} \mathrm{~min}^{-1}$ $W_{\text {cat }}=1 \mathrm{~g}, P=1$ bar. Conditions in c): $\mathrm{C}_{2} \mathrm{H}_{5} \mathrm{X}: \mathrm{HX}: \mathrm{O}_{2}: \mathrm{Ar}: \mathrm{He}=1: 6: 3: 4.5: 85.5$, $F_{\mathrm{T}}=100 \mathrm{~cm}^{3} \mathrm{~min}^{-1}, W_{\text {cat }}=1 \mathrm{~g}, P=1$ bar.

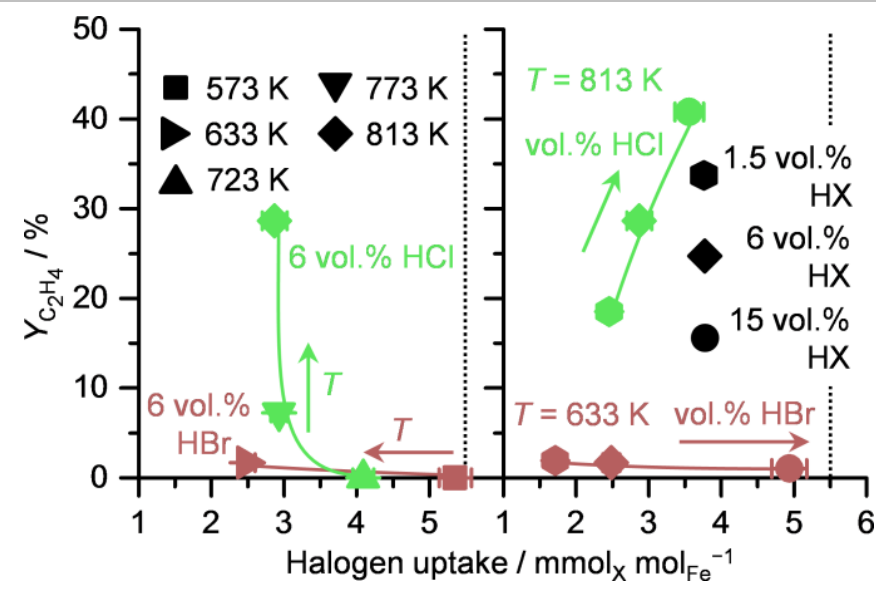

Figure 3. Yield of ethylene as a function of halogen uptake in ethane oxyhalogenation at different temperatures and $\mathrm{HX}(X=\mathrm{Cl}, \mathrm{Br})$ inlet concentration as determined in operando PGAA. More details on the working principles of this technique are summarized in Scheme S1. Conditions: $\mathrm{C}_{2} \mathrm{H}_{6}: \mathrm{HX}: \mathrm{O}_{2}: \mathrm{Ar}: \mathrm{He}=6: 6: 3: 4.5: 80.5, F_{\mathrm{T}}=100 \mathrm{~cm}^{3} \mathrm{~min}^{-1}, W_{\text {cat }}=1 \mathrm{~g}, P=1$ bar. The dotted lines represent the calculated halogen uptake corresponding to full surface coverage. The error bars of the measured halogen uptake is presented for each catalytic point.

and products, including radical intermediates in both ethane oxychlorination and oxybromination (Figures 1, 4, S6-S11). ${ }^{[8]}$ In particular, the evolution of reaction intermediate signals as a function of temperature was correlated with that of the reaction products: while the $\mathrm{Br}_{2}$ signal decreased sharply, the signals of $\mathrm{C}_{2} \mathrm{H}_{5}{ }^{\circ}$ and $\mathrm{Br}$. radicals increased along with $\mathrm{C}_{2} \mathrm{H}_{5} \mathrm{Br}$ until $600 \mathrm{~K}$. At higher temperatures, the signal of $\mathrm{C}_{2} \mathrm{H}_{5} \mathrm{Br}$ dropped to zero, while that of the radicals and $\mathrm{C}_{2} \mathrm{H}_{4}$ increased, which is consistent with a higher rate of dehydrobromination compared to ethyl bromide generation (Figures 4, S8). On the other hand, neither $\mathrm{Cl}_{2}$ nor $\mathrm{Cl}^{\cdot}$ radicals were observed under oxychlorination conditions in the investigated temperature range, in line with the DFT results. Furthermore, $\mathrm{C}_{2} \mathrm{H}_{5} \mathrm{Cl}$ was observed to decrease sharply with temperature, while $\mathrm{C}_{2} \mathrm{H}_{4}$ increased, corroborating the occurrence of a consecutive mechanism in which ethane is transformed into ethyl halide that is consequently dehydrohalogenated to $\mathrm{C}_{2} \mathrm{H}_{4}$, as also evidenced in steady-state experiments (Figure S2). Finally, measurements conducted using an empty reactor showed no production of radicals or products (Figures S10, S11)

Computational investigations at the molecular level revealed that all the elementary steps in the gas-phase pathways of oxybromination were barrierless. In addition, ethane or ethyl bromide activation with a $\mathrm{Br}^{*}$ radical to form $\mathrm{HBr}$, is endothermic by only $0.5 \mathrm{eV}$, while recombination of the produced radicals with $\mathrm{Br}^{*}$ to form $\mathrm{C}_{2} \mathrm{H}_{5} \mathrm{Br}$ or $\mathrm{C}_{2} \mathrm{H}_{4} \mathrm{Br}_{2}$, which is occurring with a comparable collision frequency as activation, is strongly exothermic $(>2.5 \mathrm{eV}$, Figure S13). This entails that, once a bromine radical evolves from the surface, it will directly activate ethane or ethyl bromide, or consume any hydrocarbon radicals by recombination, allowing inordinate polybromination instead of ethylene generation. Additionally, this mechanism of ethane activation can explain the apparent lower activation energy for ethane conversion in oxybromination, as shown in Figure $\mathbf{2 a}$, which consistently opposes the DFT results for surface-catalyzed alkane activation in this reaction (Figure $\mathbf{S 1 4}$ ). Still, $\mathrm{C}_{2} \mathrm{H}_{5}{ }^{\circ}$ radicals were observed by operando PEPICO in oxychlorination as well, and its signal increased with the reaction temperature (Figure 4). Its occurrence in oxychlorination, in which the gas-phase contributions are negligible, points to its role as intermediate in the surface-confined 


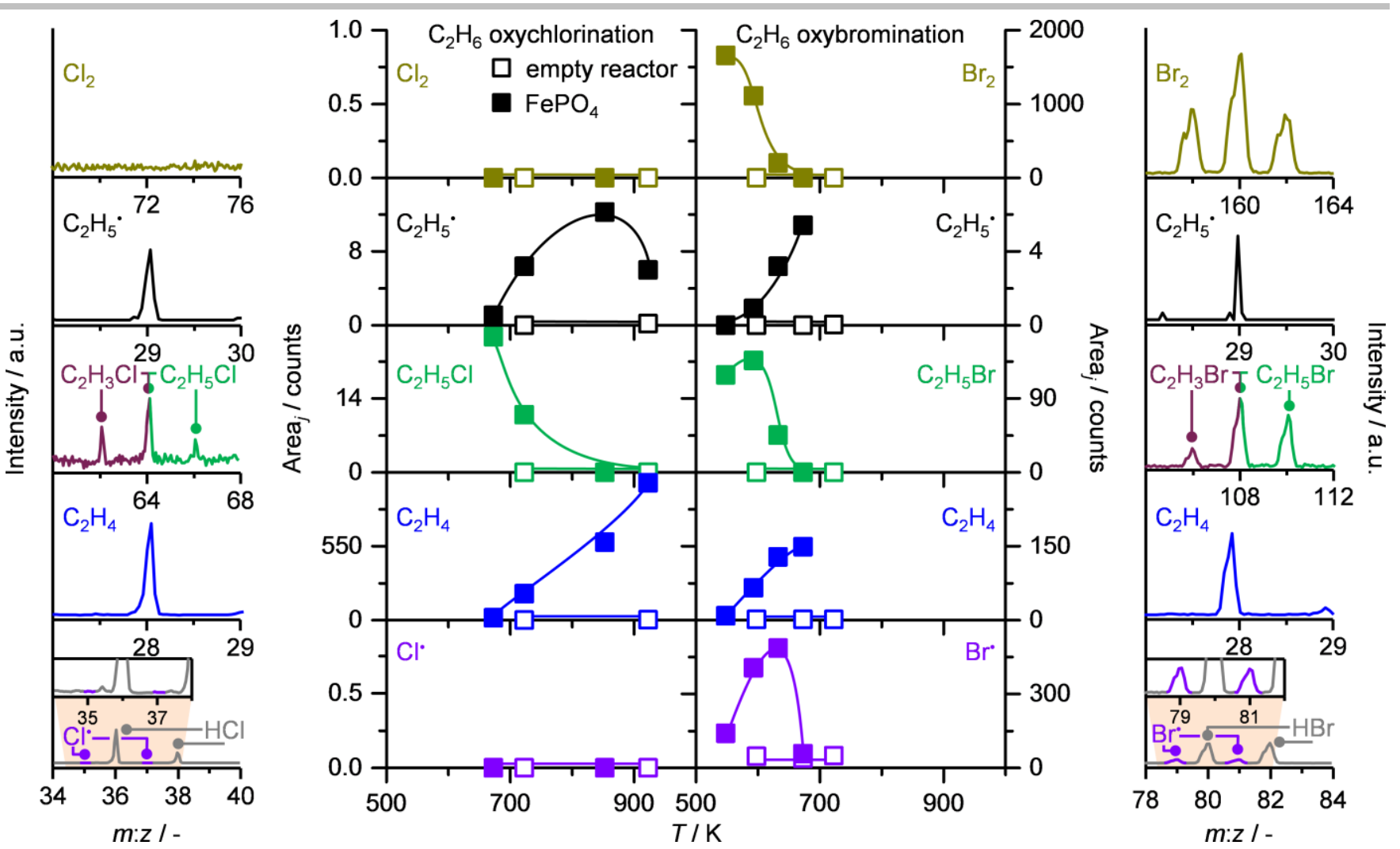

Figure 4. Extracted peak areas corresponding to molecular halogen, ethyl radical, ethyl halide, ethylene, and halogen radical as a function of temperature in the oxychlorination and oxybromination of ethane over $\mathrm{FePO}_{4}$ and using an empty reactor as determined in operando PEPICO (middle panel). More details on the working principles of this technique are summarized in Scheme S2. The left and right panels illustrate the representative mass spectra of reactants, products, and intermediate radical species detected in ethane oxychlorination and oxybromination over $\mathrm{FePO}_{4}$ at $723 \mathrm{~K}$ and $593 \mathrm{~K}$, respectively. Conditions: $\mathrm{C}_{2} \mathrm{H}_{6}: \mathrm{HX}: \mathrm{O}_{2}: \mathrm{Ar}=2: 2: 1: 17, \mathrm{FT}_{\mathrm{T}}=22 \mathrm{~cm}^{3} \mathrm{~min}^{-1}, W_{\text {cat }}=0.05$ or $0 \mathrm{~g}, P=2 \times 10^{-2}$ bar. The photon energies at which the signals of each chemical species were recorded in all PEPICO experiments are shown in Figures S6-S11.

mechanism, while its spectroscopic detection can be rationalized owing to its easy desorption from the catalyst (endothermic by $0.47 \mathrm{eV}$, Figures 5, S5, S14-S18), and the low reaction pressures (ca. $2 \times 10^{-2}$ bar). In general, surface oxyhalogenation reactions require an Fe site with a neighboring oxygen and its halogened counterpart, the latter being more prominent in oxychlorination as determined by operando PGAA (Figure 3), which are responsible for ethane activation an $d$ for ethyl halide dehydrohalogenation, respectively (Figure S14, Table S3). In particular, the former site allows for the halogen independent $\mathrm{H}$ stripping from ethane $\left(E_{\mathrm{a}}=0.61 \mathrm{eV}\right.$, Figure 5), which is however unlikely to catalyze $\mathrm{H}$ stripping from ethyl halide $\left(E_{\mathrm{a}}>2.10 \mathrm{eV}\right.$, Figure S14). Ethyl halide is formed through barrierless halogen addition to a surface-bound $\mathrm{C}_{2} \mathrm{H}_{5}{ }^{\circ}$ species (Figures S14-S18), which entails that only a small fraction evolves to the gas-phase, provided a halogen atom is close. Further transformation of ethyl halide to ethylene requires a halogenated Fe site, where the halogen strips a hydrogen generating the halide, thus closing the halogen cycle and highlighting the importance of surface halogen coverage for olefin formation. A chlorinated site favors this step by $0.18 \mathrm{eV}$ over the brominated analogue (Figure S14), in line with the observed $40 \mathrm{~K}$ light-off temperature shift in the dehydrohalogenation of ethyl halide (Figure S3). Further, $\mathrm{Cl}$ stripping from the $\mathrm{C}_{2} \mathrm{H}_{4} \mathrm{X}$ intermediate to form $\mathrm{C}_{2} \mathrm{H}_{4}\left(E_{\mathrm{a}}=0.67 \mathrm{eV}\right)$ is favored over $\mathrm{Br}$ stripping $\left(E_{\mathrm{a}}=1.50 \mathrm{eV}\right.$; Figure S14). However, considering the different surface halogenation degree in oxychlorination and oxybromination as determined by operando PGAA and the possibility that a halogenated site enables concerted $\mathrm{H}$ and $\mathrm{Cl}$ abstraction from ethyl halide (Figure S14), which is favored over the individual steps by $0.29 \mathrm{eV}$, the most likely situation is that dehydrochlorination happens in a concerted pathway on a chlorinated Fe site, while dehydrobromination occurs on an oxidic site in two individual steps (Figures 5, S16-S18). It is noteworthy that in addition to the critical role that the halogen assumes in ethyl halide activation, it is even indirectly involved in ethane activation with oxygen, as evidenced by the complete absence of $\mathrm{C}_{2} \mathrm{H}_{5} \cdot$ radicals in the PEPICO studies with halide-free feeds (Figures S7, S9), and corroborated by the promoting effect of chlorine in oxidative dehydrogenation. ${ }^{[2 a, 9]}$ This can be explained by the change of the oxidation state of iron upon halogen adsorption and the resulting structural rearrangement of the surface (Figure S19), as indicated by a Bader charge analysis (Table S4). ${ }^{[10]}$ Thus, these changes of the electronic structure allow easier ethane activation when spectator halogen species are present, in contrast to a clean surface where the ethane activation has to overcome a $1.11 \mathrm{eV}$ larger energy barrier.

In conclusion, we unraveled the mechanistic origin of the distinct selectivity patterns between ethane oxychlorination and oxybromination over iron phosphate by a multi-technique approach, combining evidence from steady-state kinetics, operando PGAA and PEPICO spectroscopies, ultimately rationalized by theoretical calculations. The sharp selectivity control in oxychlorination is achieved via a purely surface-driven functionalization of ethane into ethyl chloride, which is further dehydrochlorinated to ethylene over a $\mathrm{Cl}-\mathrm{Fe}$ center. In contrast, alkane activation to ethyl bromide in oxybromination occurs in the gas-phase with evolved bromine and 


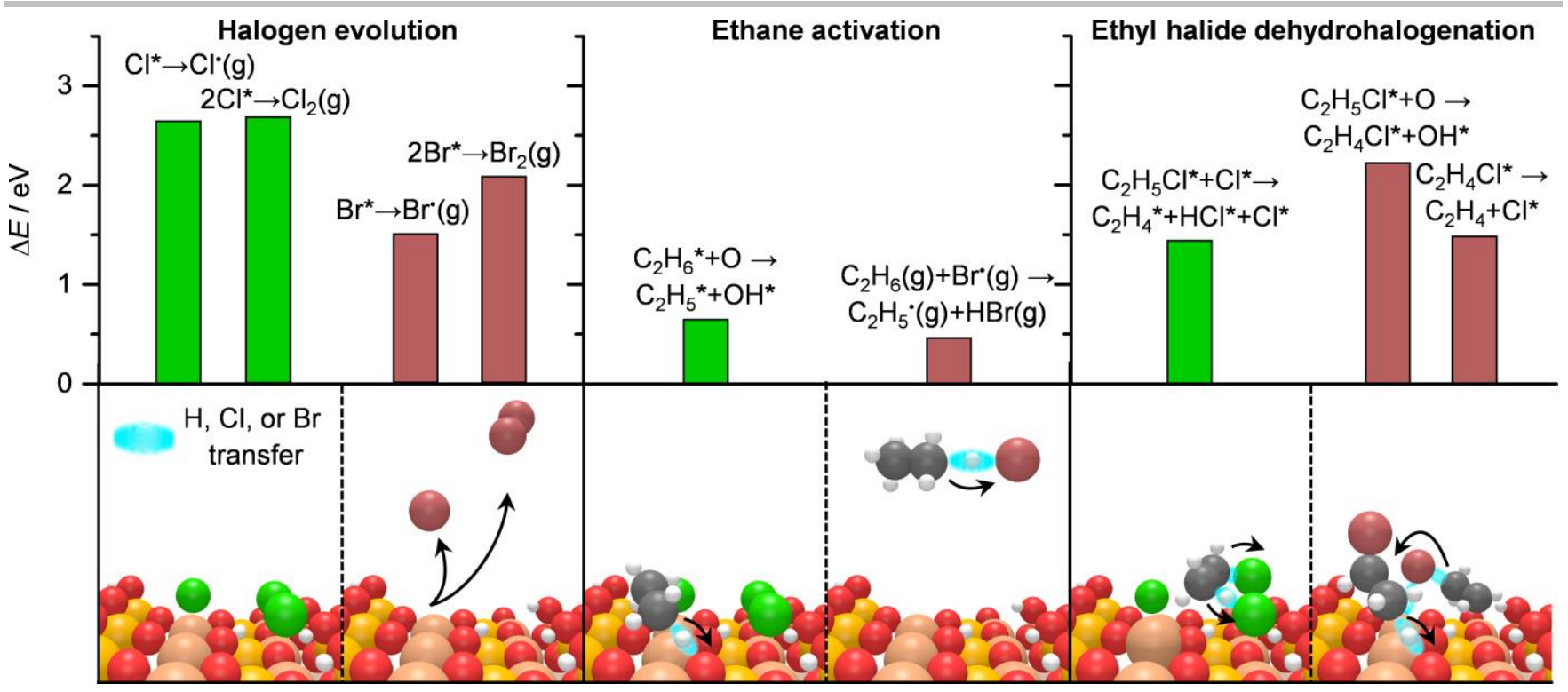

Figure 5. Energy barriers for halogen evolution (top left panel), ethane activation (top center panel), and ethyl halide dehydrohalogenation (top right panel) in ethane oxyhalogenation over a halogenated $\mathrm{FePO}_{4}(102)$ surface. The bottom panels illustrate the events corresponding to the respective bar plots that occur over the surface or in the gas-phase. Color code: Fe: light brown, $\mathrm{P}$ : yellow, O: red, $\mathrm{Cl}$ : green, Br: brown, C: gray, $\mathrm{H}$ : white. The complete reaction profile of the depicted most likely steps is provided in Figure S18.

bromine radical species, thus leaving a halogen-free surface that is more prone to additional cracking and combustion pathways. These results demonstrate that chlorine-based processes hold great potential for one-step olefin production in technical scale and provide guidelines for catalyst design for direct alkane-to-olefins transformation via oxyhalogenation. Furthermore, they provide a strategy that enables to unravel a detailed mechanistic picture in a complex reaction network, which is the typical scenario encountered in virtually all hydrocarbon functionalization processes.

\section{Experimental Section}

Details on the catalyst preparation, characterization, and evaluation as well as on operando PGAA and PEPICO techniques and DFT calculations are provided in the Supporting Information.

\section{Acknowledgements}

This work was supported by ETH Research Grant ETH-04 16-1. P.H. and A.B. acknowledge funding by the SFOE (SI/501269-01). L.S thanks the János Bolyai Research Fellowship of the Hungarian Academy of Sciences, as well as the Project No. 124068 of the National Research, Development and Innovation Fund of Hungary, financed under the K_17 funding scheme. We thank the Budapest Neutron Centre's transnational user access program for funding the PGAA beamtime. The authors thank Prof. Ralph Spolenak for access to Raman spectroscopy and Dr. Detre Teschner for providing accessories to the PGAA experiments. We thank the assistance of All Saadun, Boglárka Maróti, and Ildikó Harsányi, and Florian Goedicke in the PGAA and the PEPICO measurements, respectively.

Keywords: catalyzed alkane oxyhalogenation $•$ density functional theory $\bullet$ olefin selectivity $\bullet$ operando spectroscopies $\bullet$ reaction mechanism

[1] a) R. Lin, A. P. Amrute, J. Pérez-Ramírez, Chem. Rev. 2017, 117, 4182-4247; b) E. McFarland, Science 2012, 338, 340-342; c) H. Schwarz, Angew. Chem. Int. Ed. 2011, 50, 10096-10115; Angew. Chem. 2011, 123, 10276-10297; d) J. J. Sattler, J. Ruiz-Martinez, E. Santillan-Jimenez, B. M. Weckhuysen, Chem. Rev. 2014, 114, 10613-10653; e) J. F. Hartwig, J. Am. Chem. Soc. 2016, 138, 2-24; f) R. Horn, R. Schlögl, Catal. Lett. 2014, 145, 23-39; g) A. I. OlivosSuarez, À. Szécsényi, E. J. M. Hensen, J. Ruiz-Martinez, E. A. Pidko, J. Gascon, ACS Catal. 2016, 6, 2965-2981.

[2] a) C. A. Gärtner, A. C. van Veen, J. A. Lercher, ChemCatChem 2013, 5, 3196-3217; b) F. Cavani, N. Ballarini, A. Cericola, Catal. Today 2007, 127, 113-131 c) K. Kwapien, J. Paier, J. Sauer, M. Geske, U. Zavyalova, R. Horn, P. Schwach, A. Trunschke, R. Schlögl, Angew. Chem. Int. Ed. 2014, 53, 8774-8778; Angew. Chem. 2014, 126, 8919-8923; d) C. A. Carrero, R. Schlöegl, I. E. Wachs, R. Schomäcker, ACS Catal. 2014, 4, 3357-3380; e) V. Paunović, P. Hemberger, A. Bodi, N. López, J. Pérez-Ramírez, Nat. Catal. 2018, 1, 363-370.

[3] G. Zichittella, N. Aellen, V. Paunović, A. P. Amrute, J. Pérez-Ramírez, Angew. Chem. Int. Ed. 2017, 56, 13670-13674; Angew. Chem. 2017, 129, 1385813862.

[4] a) V. Paunović, G. Zichittella, M. Moser, A. P. Amrute, J. Pérez-Ramírez, Nat. Chem. 2016, 8, 803-809; b) G. Zichittella, B. Puértolas, V. Paunović, T. Block R. Pöttgen, J. Pérez-Ramírez, Catal. Sci. Technol. 2018, 8, 2231-2243; c) G. Zichittella, B. Puértolas, S. Siol, V. Paunović, S. Mitchell, J. Pérez-Ramírez, ChemCatChem 2018, 10, 1282-1290.

[5] U. Olsbye, O. V. Saure, N. B. Muddada, S. Bordiga, C. Lamberti, M. H. Nilsen, K. P. Lillerud, S. Svelle, Catal. Today 2011, 171, 211-220.

[6] G. L. Molnár, Handbook of Prompt Gamma Activation Analysis with Neutron Beams, Springer, 2004.

[7] Z. Révay, T. Belgya, L. Szentmiklósi, Z. Kis, A. Wootsch, D. Teschner, M. Swoboda, R. Schlögl, J. Borsodi, R. Zepernick, Anal. Chem. 2008, 80, 6066-6071. 
[8] a) D. L. Osborn, C. C. Hayden, P. Hemberger, A. Bodi, K. Voronova, B. Sztaray, J. Chem. Phys. 2016, 145, 164202; b) X. Tang, G. A. Garcia, L. Nahon, J. Phys. Chem., A 2015, 119, 5942-5950; c) P. Osswald, P. Hemberger, T. Bierkandt, E. Akyildiz, M. Kohler, A. Bodi, T. Gerber, T. Kasper, Rev. Sci. Instrum. 2014, 85, 025101; d) P. Hemberger, V. B. F. Custodis, A. Bodi, T. Gerber, J. A. van Bokhoven, Nat. Commun. 2017, 8, 15946; e) P. Hemberger, A. J. Trevitt, T. Gerber, E. Ross, G. da Silva, J. Phys. Chem., A 2014, 118, 3593-3604.

[9] C. P. Kumar, S. Gaab, T. E. Müller, J. A. Lercher, Top. Catal. 2008, 50, 156-167.

[10] A. Walsh, A. A. Sokol, J. Buckeridge, D. O. Scanlon, C. R. A. Catlow, Nat. Mater. 2018, 17, 958-964.

Supporting information, including catalyst preparation, characterization, and evaluation, descriptions of the operando PGAA and PEPICO techniques, DFT calculations, and the ORCID identification number(s) for the author(s) of this article can be found under: https://doi.org/10.1002/anie.201811669. 